\title{
International Journal of Research in Pharmaceutical sciences and Technology
}

\section{Novel approaches to enhance oral bioavailability of poorly soluble drugs}

\author{
Buduru Gowthami*1, S.V. Gopala Krishna ${ }^{2}$ and D. Subba Rao ${ }^{3}$ \\ ${ }^{1}$ Research Scholar, Faculty of Pharmaceutical Sciences, J.N.T.U.A Ananthapuramu-515002, Andhra Pradesh, India. \\ ${ }^{2}$ Department of Pharmacognosy, Vagdevi College of Pharmacy and Research Centre, Brahmadevam, Nellore-524001, Andhra \\ Pradesh, India.
}

${ }^{3}$ Department of Chemical Engineering, J.N.T.U.A Ananthapuramu-515002, Andhra Pradesh, India.

\begin{tabular}{l} 
ABSTRACT \\
\hline Oral administration is considered as major, convenient route among all other routes of delivery, owing to \\
several benefits. But, the poor solubility or enzymatic/metabolic activity are the major concerns in develop- \\
ing a successful formulation. About 40\% of approved drugs which are in the current market and $90 \%$ of new \\
drug molecules in the developmental pipeline are hydrophobic in nature. The challenge to formulate insol- \\
uble drugs has met with various approaches to overcome the problems related to solubility, application of \\
nanotechnology is one amongst them. The present review deals with various nanocarriers and technologies \\
that are proven to be effective in enhancing the bioavilability of poorly soluble drugs. \\
\hline \hline Keywords: Lipids; Polymers; Oral Bioavailability; Nanoparticles; Nanoemulsions, Nanofibers.
\end{tabular}

ISSN: 2581-9143

Research Article

Corresponding Author

Name: Buduru Gowthami

Email: gowthu.buduru@gmail.com

\begin{tabular}{l}
\hline Article Info \\
\hline \hline Received on: $29-07-2020$ \\
Revised on: $18-08-2020$ \\
Accepted on: 18-09-2020 \\
\hline \hline D0I: https://doi.org/10.33974/ijrpst.v2i1.231 \\
\hline Pubatosis \\
Copyright@ 2020, Buduru Gowthami, Novel ap- \\
proaches to enhance oral bioavailability of poorly \\
soluble drugs, Production and hosting by Ruba- \\
tosis Publications.
\end{tabular}

\section{INTRODUCTION}

Oral drug delivery is considered as most suitable, common and broadly used as it offers many advantages in the vein of patient compliance and cost in contrast to other routes such as mucosal, transdermal and pulmonary [1]. Nevertheless, numerous compounds are ineffective and fails in research and development process owing to their low solubility, thus minimising the absorption and bioavailability [2-3]. As estimated, nearly $40 \%$ of approved drugs and $90 \%$ of molecules in the development stages are suffering with the solubility issues. Some of the reasons for this are as follows; i) Unavailability of drug in solution form, ii) first pass metabolism, iii) inadequate partition coefficient, iv) degradation of drug in gastro intestinal tract and v) p-glycoprotein mediated efflux (which can alter the pharmacokinetics) [4]. Quite a few approaches have been applied to enhance the oral absorption and bioavailability of hydrophobic drugs such as, hydrotrophy, micronization and solid dispersions. Since few years, nanocarriers are attain incredible attention and have shown notable advantages over conventional systems, especially for low soluble drugs [5].

\section{Traditional methodologies in enhancing the solu- bility}

Several conventional methods like Co-solvency and surfactant solubilisation; $\mathrm{pH}$ modification, microparticles [6,7] and salt forms; Cyclodextrins (CDs); solid state modification including, amorphous forms, solid dispersions and co-crystals etc. CDs (Inclusion complexation) are the are the multipurpose excipients studied widely for pharmaceutical purposes. Solid dispersion is one of the technology that is explored broadly in the recent decades specially for the delivery of low soluble drugs [8]. Localization of conventional dosage forms can also results in enhancing the bioavailability as evident from several studies on coating [9], mucoadhesion [10,11], and floating approaches [12]. Fast dissolving tablets and matrix dosage forms are also established their application in enhancing the absorption [13,14].

\section{Novel technologies in delivery of poorly soluble drugs}

The most frequent nanotechnology based strategies used in the formulation development are solid lipid nanoparticles, polymeric nanoparticles, dendrimers, liposomes, micelles, carobon nanotubes and so forth [Figure 1]. which an further provide controlled or 


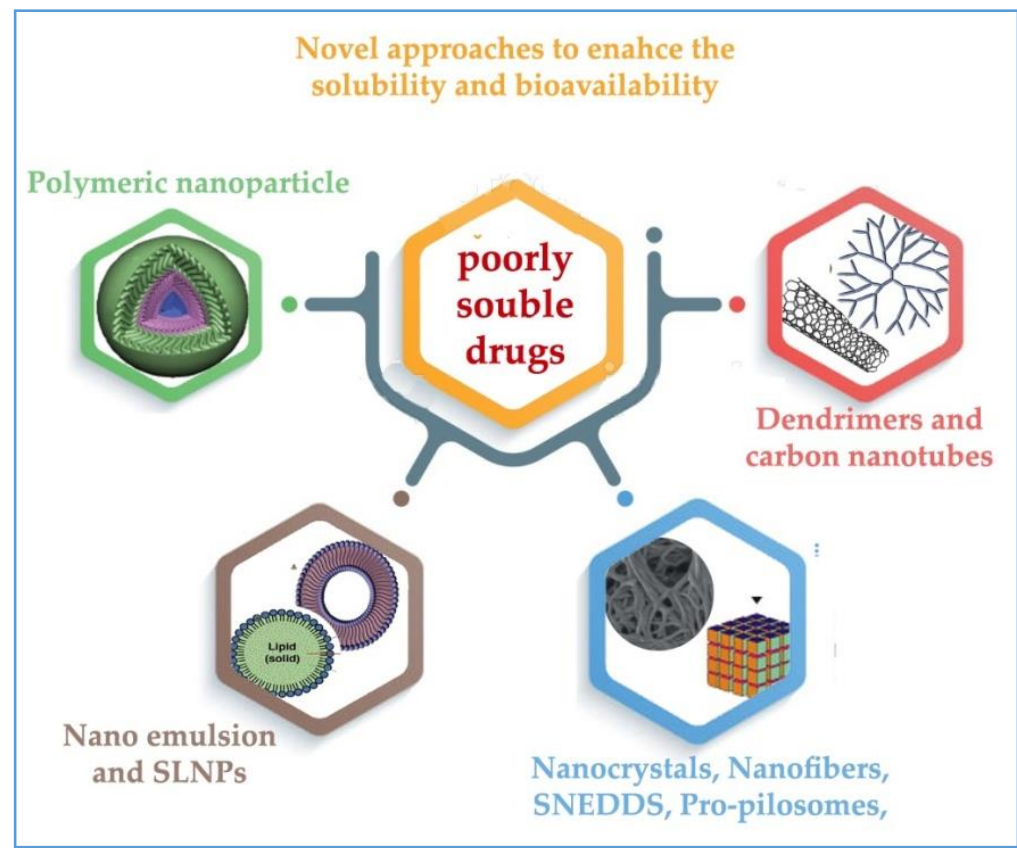

Figure 1: Some of the novel approaches to enhance the solubility and bioavailability of poorly soluble drugs

sustained or targeted drug delivery. At this time, all these novel systems are explored effectively in enhancing the therapeutic efficacy especially in anticancer, anti-diabetic and non-steroidal anti-inflammatory drugs etc.

Polymeric nanoparticles are the colloidal carriers having particle size in the range of 10-100 nm. Application of polymeric nanoparticles can enhance the bioavailability, specificity and reduce toxicity. These nanoparticles can be prepared by using several natural and synthetic polymers [15-19]. These carriers were successfully employed for gene delivery and tumor targeting. The therapeutic efficacy is significantly depends on biodegradation of polymer and drug release, usually the drug release follows erosion mechanism, diffusion mechanism of combination of both [20].

Solid Lipid nanoparticles (SLN) are the sub-micron colloidal carriers, which were composed of physiological lipids, which are dispersed in aqueous or aqueous surfactant solution. SLNs can offer other benefits such as non-toxicity, biocompatibility and stability, that can be applied for the delivery of hydrophobic as well as hydrophillic drugs [21].

Nanoemulsions are 0/W type on emulsions having the droplet size of 100-500 $\mathrm{nm}$ and can provide advantages like solubilization of poorly soluble drugs in the oil phase and modifies the oil droplet with polymers to prolong the circulation time and also to target several tumors passively or actively (by adding ligands) [22]. Commonly used methods are double emulsion, low and high energy emulsification etc. SNEDDS (Self nano emulsifying drug delivery systems) are anhydrous hydrotrophic mixture of surfactant, oil and drug, subsequently added to the aqueous phase with continuous stirring to form the SNEDDS. Apart from the benefits of nanoemulsions, SNEDDS can further enhances the chemical, enzymatic stability of drug molecule, and ease of scale up and fabrication [23].

Nanocrystals are having the atoms size in the range of 10-400 nm, prepared from nanosuspension consisting of the following steps. i) preparation of nanosuspension, ii) wet milling, iii) high pressure homogenization iv) nanocrystallization and v) spray drying [24,25]. Mallesh Kurakula et al., have investigated the efficacy of nanocrystals in enhancing the solubility and dissolution rate of Atorvastatin [26].

Proliposomes are dry, free flowing powder with a dispersed system, which can immediately form a liposomal suspension on contact with water. Owing to their solid properties, proliposomes can enhance the physical stability and promote drug absorption [27-31].

Dendrimers are the novel innovative polymeric carrier having three dimensional structure, narrow polydispersity index, controlled molecular structure and accompanied with several multiple functional groups. Dendrimers having the size in between 1 to $100 \mathrm{~nm}$ with three distinct domains i) core, containing a molecule or atom, ii) repeated branches and iii) terminal functional groups. Currently, carbon nanotubes are gaining remarkable attention as novel carriers owing to their unique features such as a) higher cellular uptake, ii) enhanced transmembrane penetration and iii) high drug loading [32]. Apart from all these novel systems, nanowires, nanofibers, nanoethanosomes and nanofilms are gained their importance in enhancing the oral bioavailability of poorly soluble drugs [33-38]. Though the optimizing of several parameters in preparing optimum nano-formulation is bit complicated, several applications like quality by design/ response surface methodology or PAT can be successfully applied [39-44]. 


\section{CONCLUSION}

Application of nanotechnology holds a great potential in the effective delivery of several poorly soluble drugs. All the foresaid technologies are appeared as various strategies to revitalize the current development process. The colloidal size, low dose size reduced toxicity and patient compliance are the main benefits, adding a special note to drug targeting. Several research works were revealed this. Even though the several significant achievements are made in nano field, yet there are few challenges that have been encountered, like a) scale up, b) variation of pharmacokinetics among the individuals and c) cost and d) reproducibility. Thus, nanotechnology can offers several opportunities for the researchers to extend their research and development to overcome the foresaid challenges.

\section{REFERENCES}

1. Naveen, N.R., Gopinath, C., Rao, D.S. (2017) Design expert supported mathematical optimization of repaglinide gastroretentive floating tablets: In vitro and in vivo evaluation. Future J. Pharm. Sci. 3(2):140-147.

https://doi.org/10.1016/j.fjps.2017.05.003

2. U Agrawal, R Sharma, M Gupta, S.P.Vyas,. (2014) Is nanotechnology a boon for oral drug delivery? Drug Discovery Today, 19(10) 1530-1546.

3. Naveen, N. R., Gopinath, C., \& Kurakula, M. (2020). Okra-thioglycolic acid conjugate-synthesis, characterization, and evaluation as a mucoadhesive polymer. Processes, 8(3), 316. https://doi.org/10.3390/pr8030316

4. T. Hetal, P. Bindesh, and T. Sneha, (2010) A review on techniquesfor oral bioavailability enhancement of drugs, InternationalJournal of Pharmaceutical Sciences Review and Research,4 (3) 203223.

5. T Mallamma, DR Bharathi, RG Lakshmi, T Vyjayanthimala, J Nagasubbareddy, R Naveen (2014), Etoposide-loaded nanoparticles made from poly-e-caprolactone (PCL): formulation, characterization, in vitro drug release for controlled drug delivery system, Int. J. Biopharm 5, 512

6. Alhakamy, N. A., Fahmy, U. A., Ahmed, O. A. A., Caruso, G., Caraci, F., Asfour, H. Z., Bakhrebah, M. A., Alomary, M. N., Abdulaal, W. H., Okbazghi, S. Z., Abdel-Naim, A. B., Eid, B. G., Aldawsari, H. M., Kurakula, M., \& Mohamed, A. I. (2020). Chitosan coated microparticles enhance simvastatin colon targeting and pro-apoptotic activity. Marine Drugs, 18(4), 226. https://doi.org/10.3390/md18040226

7. Alhakamy, N. A., Ahmed, O. A. A., Kurakula, M., Caruso, G., Caraci, F., Asfour, H. Z., Alfarsi, A., Eid, B. G., Mohamed, A. I., Alruwaili, N. K., Abdulaal, W. H.,
Fahmy, U. A., Alhadrami, H. A., Eldakhakhny, B. M., \& Abdel-Naim, A. B. (2020). Chitosan-based microparticles enhance ellagic acid's colon targeting and proapoptotic activity. Pharmaceutics, 12(7), 1-14. $\quad$ https://doi.org/10.3390/pharmaceutics12070652

8. Vanitasagar, S., Srinivas, C., Subhashini, N. J. P., \& Mallesh, K. (2012). Solid dispersion-a comparative study on the dissolution rate of aceclofenac. International Journal of Pharmacy and Pharmaceutical Sciences, 4(SUPPL.3), 274-278.

9. Kurakula, M., Naveen, N. R., \& Yadav, K. S. (2020). Formulations for Polymer Coatings. Polymer Coatings, 415-443. https://doi.org/10.1002/9781119655145.ch19

10. NR Naveen, C Gopinath, DS Rao, (2018), A spotlight on thiolated natural polymers and their relevance in mucoadhesive drug delivery system, $\mathrm{Fu}$ ture J. Pharm. Sci.4 (1), 47-52

11. NR Naveen, C Gopinath, DS Rao (2017), Isolation and assessment of natural mucoadhesive agent isolated from Abelmoschus esculents, Journal of Pharmacy Research 11 (5), 438-443

12. NR Naveen, TS Nagaraja, DR Bharathi, JNS Reddy (2013), Formulation Design and In Vitro Evaluation for Stomach Specific Drug Delivery System of Anti Retroviral drug-Acyclovir, International Journal of Pharmacy and Life Sciences 4 (3), 25062510.

13. DRB P. Divya, N. Raghavendra Naveen, Snehalatha (2013), Optimization of cross linked tragacanth and comparison of drug Release rate profile with synthetic superdisintegrants on Metoclopramide orodispersible tablets, International journal of pharmacy and life sciences 4 (3), 2500-2505.

14. NR Naveen, (2013) Design and characterization of sustained release matrix tablets of glimepiride by using synthetic and natural polymers, International journal of drug discovery and herbal research 3 (1), 573-578

15. Hasnain, M. S., Kiran, V., Kurakula, M., Rao, G. K., Tabish, M., \& Nayak, A. K. (2020). Use of alginates for drug delivery in dentistry. In Alginates in Drug Delivery (pp. 387-404). Elsevier. https://doi.org/10.1016/b978-0-12-8176405.00015-7

16. Hasnain, M. S., Nayak, A. K., Kurakula, M., \& Hoda, M. N. (2020). Alginate nanoparticles in drug delivery. In Alginates in Drug Delivery (pp. 129-152). Elsevier. https://doi.org/10.1016/b978-0-12817640-5.00006-6

17. Kurakula, M., Rao, G. K., Kiran, V., Hasnain, M. S., \& Nayak, A. K. (2020). Alginate-based hydrogel systems for drug releasing in wound healing. In Alginates in Drug Delivery (pp. 323-358). Elsevier. 
https://doi.org/10.1016/b978-0-12-817640$\underline{5.00013-3}$

18. Kurakula, M., \& Rao, G. S. N. K. (2020). Type of Article: REVIEW Pharmaceutical Assessment of Polyvinylpyrrolidone (PVP): As Excipient from Conventional to Controlled Delivery Systems with a Spotlight on COVID-19 Inhibition. Journal of Drug Delivery Science and Technology, 102046.

19. Naguib, Ghada Hussein, Al-Hazmi, F. E., Kurakula, M., Abdulaziz Al-Dharrab, A., Mohamed Hosny, K., Mohammed Alkhalidi, H., Tharwat Hamed, M., Habiballah Hassan, A., Al-Mohammadi, A. M., Mohamed Alnowaiser, A., \& Henry Pashley, D. (2018). Zein coated zinc oxide nanoparticles: Fabrication and antimicrobial evaluation as dental aid. International Journal of Pharmacology, 14(8), 10511059.

https://doi.org/10.3923/ijp.2018.1051.1059

20. Kurakula, M., \& Raghavendra Naveen, N. (2020). In situ gel loaded with chitosan-coated simvastatin nanoparticles: Promising delivery for effective anti-proliferative activity against tongue carcinoma. Marine Drugs, 18(4), 201. https://doi.org/10.3390/md18040201

21. Kurakula, M., Ahmed, O. A. A., Fahmy, U. A., \& Ahmed, T. A. (2016). Solid lipid nanoparticles for transdermal delivery of avanafil: optimization, formulation, in-vitro and ex-vivo studies. Journal of Liposome Research, 26(4), 288-296. https://doi.org/10.3109/08982104.2015.11174 $\underline{90}$

22.Hosny, K. M., Aldawsari, H. M., Bahmdan, R. H., Sindi, A. M., Kurakula, M., Alrobaian, M. M., Aldryhim, A. Y., Alkhalidi, H. M., Bahmdan, H. H., Khallaf, R. A., \& El Sisi, A. M. (2019). Preparation, Optimization, and Evaluation of Hyaluronic AcidBased Hydrogel Loaded with Miconazole SelfNanoemulsion for the Treatment of Oral Thrush. AAPS PharmSciTech, 20(7), 297. https://doi.org/10.1208/s12249-019-1496-7

23. Venkatesh, M., \& Mallesh, K. (2013). Self-Nano Emulsifying Drug Delivery System (SNEDDS) for Oral Delivery of Atorvastatin- Formulation and Bioavailability Studies. Journal of Drug Delivery and Therapeutics, 3(3), 131-140. https://doi.org/10.22270/jddt.v3i3.517

24. Kurakula, M., El-Helw, A. M., Sobahi, T. R., \& Abdelaal, M. Y. (2015). Chitosan based atorvastatin nanocrystals: Effect of cationic charge on particle size, formulation stability, and in-vivo efficacy. International Journal of Nanomedicine, 10, 321334. https://doi.org/10.2147/IJN.S77731

25. Kurakula, M., Sobahi, T. R., El-Helw, A., \& Abdelaal, M. Y. (2014). Development and validation of a RPHPLC method for assay of atorvastatin and its application in dissolution studies on thermosensi- tive hydrogel-based nanocrystals. Tropical Journal of Pharmaceutical Research, 13(10), 16811687. https://doi.org/10.4314/tjpr.v13i10.16

26. Kurakula, M., \& A. Ahmed, T. (2015). Co-Delivery of Atorvastatin Nanocrystals in PLGA based in situ Gel for Anti-Hyperlipidemic Efficacy. Current Drug Delivery, 13(2), 211-220. https://doi.org/10.2174/156720181366615110 $\underline{9102718}$

27. Ahmed, O. A. A., Kurakula, M., Banjar, Z. M., Afouna, M. I., \& Zidan, A. S. (2015). Quality by design coupled with near infrared in formulation of transdermal glimepiride liposomal films. Journal of Pharmaceutical Sciences, 104(6), 2062-2075. https://doi.org/10.1002/jps.24448

28. Kurakula, M., Srinivas, C., Kasturi, N., \& Diwan, P. V. (2012). Formulation and Evaluation of Prednisolone Proliposomal Gel for Effective Topical Pharmacotherapy. International Journal of Pharmaceutical Sciences and Drug Research, 4(1), 35. www.ijpsdr.com

29. Mallesh, K., Pasula, N., \& Kumar Ranjith, C. P. (2012). Piroxicam proliposomal gel: a novel approach for tropical delivery. Journal of Pharmacy Research, 5(3), 1755-1763.

30. Mallesh, K, Mohd, A. B., A, P. R., \& Diwan, P. V. (2011a). Estimation of Prednisolone in Proliposomal formulation using RP HPLC method. Int. J. Res. Pharm. Biomed. Sci. 2011; 2: 663, 2(4), 16631669.

31. Kurakula, M., Mohd, A. B., Rao, P. A., \& Diwan, P. V. (2011). Estimation of piroxicam in proliposomal formulation using RPHPLC method. Int. J. Chem. Anal. Sci. 2011; 2: 1193, 1196.

32. B. ShengWong, S. L. Yoong, A. Jagusiak et al., (2013) Carbon nan-otubes for delivery of small molecule drugs, Advanced Drug Delivery Reviews,.65, 15,1964-2015.

33. Abdelhady, S., Honsy, K. M., \& Kurakula, M. (2015). Electro Spun- Nanofibrous Mats: A Modern Wound Dressing Matrix with a Potential of Drug Delivery and Therapeutics. Journal of Engineered Fibers and Fabrics, 10(4), 155892501501000. https://doi.org/10.1177/155892501501000411

34. Ahmed, S., Sarim Imam, S., Zafar, A., Ali, A., Aqil, M., \& Gull, A. (2016). In vitro and preclinical assessment of factorial design based nanoethosomes transgel formulation of an opioid analgesic. Artificial Cells, Nanomedicine and Biotechnology, 44(8), 1793-1802. https://doi.org/10.3109/21691401.2015.11027 $\underline{42}$

35. Andleeb, A., \& Yar, M. (2020). Application of Electrospun Materials in Industrial Applications. Electrospun Materials and Their Allied Applications, 
215-242.

https://doi.org/10.1002/9781119655039.ch8

36. Kurakula, M., \& Koteswara Rao, G. S. N. (2020). Moving polyvinyl pyrrolidone electrospun nanofibers and bioprinted scaffolds toward multidisciplinary biomedical applications. European Polymer Journal, 136, 109919. https://doi.org/10.1016/j.eurpolymi.2020.109919.

37. Murali, V. P., Fujiwara, T., Gallop, C., Wang, Y., Wilson, J. A., Atwill, M. T., Kurakula, M., \& Bumgardner, J. D. (2020). Modified electrospun chitosan membranes for controlled release of simvastatin. International Journal of Pharmaceutics, 584, 119438.

https://doi.org/10.1016/j.ijpharm.2020.119438

38. Naguib, G. H., Hassan, A. H., Al-Hazmi, F., Kurakula, M., Al-Dharrabh, A., Alkhalidi, H. M., Al-Ahdal, A. M., Hamed, M. T., \& Pashley, D. H. (2017). Zein based magnesium oxide nanowires: Effect of anionic charge on size, release and stability. Digest Journal of Nanomaterials and Biostructures, 12(3), 741-749.

39. Raghavendra Naveen, N., Kurakula, M., \& Gowthami, B. (2020). Process optimization by response surface methodology for preparation and evaluation of methotrexate loaded chitosan nanoparticles. Materials Today: Proceedings. https://doi.org/10.1016/i.matpr.2020.01.491

40. Tsai, Y. M., Jan, W. C., Chien, C. F., Lee, W. C., Lin, L. C., \& Tsai, T. H. (2011). Optimised nano-formulation on the bioavailability of hydrophobic polyphenol, curcumin, in freely-moving rats. Food chemistry, 127(3), 918-925.

41. Rajoli, R. K., Back, D. J., Rannard, S., Meyers, C. L. F., Flexner, C., Owen, A., \& Siccardi, M. (2015). Physiologically based pharmacokinetic modelling to inform development of intramuscular long-acting nanoformulations for HIV. Clinical pharmacokinetics, 54(6), 639-650.

42. Tatham, L. M., Savage, A. C., Dwyer, A., Siccardi, M., Scott, T., Vourvahis, M.,... \& Owen, A. (2019). Towards a Maraviroc long-acting injectable nanoformulation. European Journal of Pharmaceutics and Biopharmaceutics, 138, 92-98.

43. Rajoli, R. K., Back, D. J., Rannard, S., Meyers, C. L. F., Flexner, C., Owen, A., \& Siccardi, M. (2015). Physiologically based pharmacokinetic modelling to inform development of intramuscular long-acting nanoformulations for HIV. Clinical pharmacokinetics, 54(6), 639-650.

44.Soni, K., Mujtaba, A., Akhter, M. H., Zafar, A., \& Kohli, K. (2020). Optimisation of ethosomal nanogel for topical nano-CUR and sulphoraphane delivery in effective skin cancer therapy. Journal of Microencapsulation, 37(2), 91-108. 